\title{
ELECTRONIC PARAMETER AND SUBBAND STRUCTURE VARIATIONS DUE TO AN EMBEDDED AIN POTENTIAL BARRIER LAYER IN $\mathrm{Al}_{0.3} \mathrm{Ga}_{0.7} \mathrm{~N} / \mathrm{GaN}$ HETEROSTRUCTURES
}

\author{
S. M. HAN and S. Y. KIM \\ Information Display Engineering, Hanyang University, \\ 17 Haengdang-dong, Seongdong-gu, Seoul 133-791, Korea \\ D. C. CHOO, J. I. JUNG and T. W. KIM* \\ Research Institute of Information Display, \\ Division of Electronics and Computer Engineering, Hanyang University, \\ 17 Haengdang-dong, Seongdong-gu, Seoul 133-791, Korea \\ *twk@hanyang.ac.kr \\ K. H. YOO \\ Department of Physics and Research Institute for Basic Sciences, \\ Kyung Hee University, Seoul 130-701, Korea \\ Y. H. JO and M. H. JUNG \\ Quantum Material Research Team, Korea Basic Science Institute, \\ Daejon 305-333, Korea \\ H. I. CHO and J. H. LEE \\ Department of Electric and Electronic Engineering, \\ Kyungpook National University, \\ 1370 Sangyeok-dong, Buk-ku, Daegu 702-701, Korea \\ L. R. RAM-MOHAN \\ Department of Physics, Worcester Polytechnic Institute, \\ Worcester, Massachusetts 01609, USA
}

Received 1 December 2006

\begin{abstract}
Carrier density of a two-dimensional electron gas (2DEG) in $\mathrm{Al}_{0.3} \mathrm{Ga}_{0.7} \mathrm{~N} / \mathrm{GaN}$ and $\mathrm{Al}_{0.3} \mathrm{Ga}_{0.7} \mathrm{~N} / \mathrm{AlN} / \mathrm{GaN}$ heterostructures was investigated by performing Shubnikov-de Haas $(\mathrm{SdH})$ measurements. The angular-dependent $\mathrm{SdH}$ measurements and the fast Fourier transformation results for the SdH data indicated 2DEG occupation of one subband in the triangular potential wells. The carrier densities of the 2DEGs in the $\mathrm{Al}_{0.3} \mathrm{Ga}_{0.7} \mathrm{~N} / \mathrm{AlN} / \mathrm{GaN}$ and the $\mathrm{Al}_{0.3} \mathrm{Ga}_{0.7} \mathrm{~N} / \mathrm{GaN}$ heterostructures at $1.5 \mathrm{~K}$, determined from the $\mathrm{SdH}$ data, were $1.28 \times 10^{13}$ and $1.12 \times 10^{13} \mathrm{~cm}^{-2}$, respectively. The electron carrier density of the $2 \mathrm{DEG}$ in the $\mathrm{Al}_{0.3} \mathrm{Ga}_{0.7} \mathrm{~N} / \mathrm{GaN}$ heterostructure with an AlN embedded potential barrier layer was larger than that in the $\mathrm{Al}_{0.3} \mathrm{Ga}_{0.7} \mathrm{~N} / \mathrm{GaN}$ heterostructure. The electronic subband energies, the wave functions, and the Fermi energies in the $\mathrm{Al}_{0.3} \mathrm{Ga}_{0.7} \mathrm{~N} / \mathrm{AlN} / \mathrm{GaN}$ and $\mathrm{Al}_{0.3} \mathrm{Ga}_{0.7} \mathrm{~N} / \mathrm{GaN}$ heterostructures were calculated by using a self-consistent method taking into account spontaneous and piezoelectric polarizations.
\end{abstract}

Keywords: $\mathrm{Al}_{0.3} \mathrm{Ga}_{0.7} \mathrm{~N} / \mathrm{GaN} ; \quad \mathrm{Al}_{0.3} \mathrm{Ga}_{0.7} \mathrm{~N} / \mathrm{AlN} / \mathrm{GaN} ; \quad$ electronic parameter; electronic structure.

*Corresponding author. 


\section{Introduction}

Potential applications of $\mathrm{Al}_{x} \mathrm{Ga}_{1-x} \mathrm{~N}$-based quantum structures in high-power and high-speed electronic devices have driven extensive efforts to grow high-quality films. ${ }^{1-5}$ Promising applications of the high possibilities for high-power and high-speed operations require important information of the electronic parameters affecting the carrier density and the mobility of the two-dimensional electron gas (2DEG) occupying the $\mathrm{Al}_{x} \mathrm{Ga}_{1-x} \mathrm{~N} / \mathrm{GaN}$ heterostructure because a large carrier density and high mobility of the 2DEG are necessary for achieving high efficiency devices. ${ }^{6}$ Recently, it is found that the carrier density and mobility of the 2DEG occupying the $\mathrm{Al}_{x} \mathrm{Ga}_{1-x} \mathrm{~N} / \mathrm{GaN}$ heterostructures could be significantly improved by inserting an AlN interlayer. ${ }^{7}$ Even though some studies on the magnetotransport properties of the 2DEG in the $\mathrm{Al}_{x} \mathrm{Ga}_{1-x} \mathrm{~N} / \mathrm{GaN}$ heterostructures ${ }^{8-11}$ have been performed, very few studies concerning the comparison of the electronic structures between the $\mathrm{Al}_{x} \mathrm{Ga}_{1-x} \mathrm{~N} / \mathrm{GaN}$ and $\mathrm{Al}_{x} \mathrm{Ga}_{1-x} \mathrm{~N} / \mathrm{AlN} / \mathrm{GaN}$ heterostructures have been reported. ${ }^{12}$ Therefore, systematic studies concerning the magnetotrasport and electronic subband properties in $\mathrm{Al}_{x} \mathrm{Ga}_{1-x} \mathrm{~N} / \mathrm{GaN}$ heterostructures containing different $\mathrm{Al}$ mole fractions with and without an AlN potential barrier layer are still necessary to enhance the efficiency of high power and high-speed heterostructure field-effect transistors. ${ }^{13}$

This paper reports the magnetotransport and the electronic structures of $\mathrm{Al}_{0.3} \mathrm{Ga}_{0.7} \mathrm{~N} / \mathrm{GaN}$ and $\mathrm{Al}_{0.3} \mathrm{Ga}_{0.7} \mathrm{~N} / \mathrm{AlN} / \mathrm{GaN}$ heterostructures. Shubnikov-de Haas ( $\mathrm{SdH}$ ) measurements were performed to investigate the existence of the 2DEG and to determine the carrier densities of the 2DEG occupying the $\mathrm{Al}_{0.3} \mathrm{Ga}_{0.7} \mathrm{~N} / \mathrm{GaN}$ and the $\mathrm{Al}_{0.3} \mathrm{Ga}_{0.7} \mathrm{~N} /$ AlN/GaN hetero interfaces. The electronic parameters of the 2DEGs in $\mathrm{Al}_{0.3} \mathrm{Ga}_{0.7} \mathrm{~N} / \mathrm{GaN}$ heterostructures with and without an AlN embedded barrier were compared. The electronic subband energies, the energy wavefunctions, and the Fermi energies of the $\mathrm{Al}_{0.3} \mathrm{Ga}_{0.7} \mathrm{~N} / \mathrm{AlN} / \mathrm{GaN}$ and $\mathrm{Al}_{0.3} \mathrm{Ga}_{0.7} \mathrm{~N} / \mathrm{GaN}$ heterostructures were calculated by using a selfconsistent method, taking into account the spontaneous polarization effect and the piezoelectric polarization effect.

\section{Experimental Details}

Two samples used in this study were grown on (0001)-oriented sapphire substrates by using metalorganic chemical-vapor deposition and consisted of the following structures from the top side: a $30 \AA$ unintentionally doped GaN capping layer for ohmic contact, a $300 \AA$ unintentionally doped $\mathrm{Al}_{0.3} \mathrm{Ga}_{0.7} \mathrm{~N}$ layer, unintentionally doped AlN spacer layers $(t=0$ or $30 \AA$ ), a $2.5-\mu \mathrm{m}$ unintentionally doped GaN active layer, and a $200 \AA$ unintentionally doped GaN buffer layer grown at low temperature. The compositions of the layers were measured by using double-crystal $\mathrm{X}$-ray diffraction measurements, and the thicknesses of the layers were determined from the growth rate and from cross-sectional transmission electron microscopy measurements. The $\mathrm{SdH}$ measurements were carried out at a temperature of $1.5 \mathrm{~K}$ in magnetic fields up to $15 \mathrm{~T}$ in an Oxford superconducting magnet system by using a Keithley 181 nanovoltmeter. Ohmic contacts to the samples were made by diffusing a small amount of indium through several layers at $200^{\circ} \mathrm{C}$ in a hydrogen atmosphere for approximately $10 \mathrm{~min}$.

\section{Results and Discussion}

$\mathrm{SdH}$ measurements were performed in order to demonstrate the existence of a 2DEG and to determine the carrier density of the 2DEG. The results of the $\mathrm{SdH}$ oscillations clearly show one frequency, indicative of the occupation of one subband by 2DEGs in the $\mathrm{Al}_{0.3} \mathrm{Ga}_{0.7} \mathrm{~N} / \mathrm{GaN}$ and $\mathrm{Al}_{0.3} \mathrm{Ga}_{0.7} \mathrm{~N} / \mathrm{AlN} / \mathrm{GaN}$ heterostructures. The 2DEG behaviors of the free-electron carriers giving rise to the $\mathrm{SdH}$ oscillations in the $\mathrm{Al}_{0.3} \mathrm{Ga}_{0.7} \mathrm{~N} / \mathrm{GaN}$ and the $\mathrm{Al}_{0.3} \mathrm{Ga}_{0.7} \mathrm{~N} / \mathrm{AlN} / \mathrm{GaN}$ heterostructures were confirmed by studies with magnetic fields oriented at $22^{\circ}$ and $23.5^{\circ}$ to the surface normal. These $\mathrm{SdH}$ oscillations of the 2DEG occupying the $\mathrm{Al}_{0.3} \mathrm{Ga}_{0.7} \mathrm{~N} / \mathrm{GaN}$ and the $\mathrm{Al}_{0.3} \mathrm{Ga}_{0.7} \mathrm{~N} / \mathrm{AlN} / \mathrm{GaN}$ hetero-interfaces varied with the angle between the magnetic field and the surface normal, indicative of the occupation of the GaN active layer by 2DEGs, as shown in Fig. 1.

After high-pass filtering and fast Fourier transformation (FFT) were performed, ${ }^{14}$ the frequency peaks of the FFTs for the $\mathrm{Al}_{0.3} \mathrm{Ga}_{0.7} \mathrm{~N} / \mathrm{GaN}$ and the $\mathrm{Al}_{0.3} \mathrm{Ga}_{0.7} \mathrm{~N} / \mathrm{AlN} / \mathrm{GaN}$ heterostructures were 230.9 


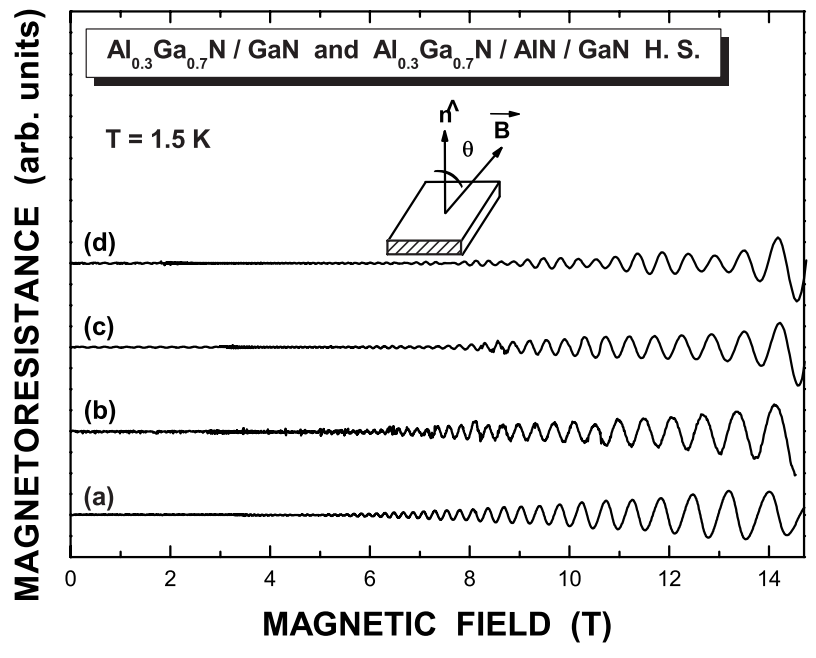

Fig. 1. $\mathrm{SdH}$ results at $1.5 \mathrm{~K}$ for an $\mathrm{Al}_{0.3} \mathrm{Ga}_{0.7} \mathrm{~N} / \mathrm{GaN}$ heterostructure with (a) $\theta=0^{\circ}$ and (b) $\theta=22^{\circ}$ and for an $\mathrm{Al}_{0.3} \mathrm{Ga}_{0.7} \mathrm{~N} / \mathrm{AlN} / \mathrm{GaN}$ heterostructure with (c) $\theta=0^{\circ}$ and (d) $\theta=23.5^{\circ}$.

and $264.6 \mathrm{~T}^{-1}$, respectively, as shown in Figs. 2(a) and $2(\mathrm{c})$. These frequencies correspond to electron density of $1.12 \times 10^{13}$ and $1.28 \times 10^{13} \mathrm{~cm}^{-2}$ for the ground-state subband. The oscillation frequencies determined by the $\mathrm{SdH}$ measurements at $1.5 \mathrm{~K}$ were shifted for measurements with the magnetic fields oriented at $22^{\circ}$ and $23.5^{\circ}$ to the normal to the sample surfaces, as shown in Figs. 2(b) and 2 (d). Since the normal component of the magnetic field oriented at $\theta$ is approximately $\cos (\theta)$ times the magnetic field at $\theta=0^{\circ}$, the oscillation peak for a magnetic field oriented at $0^{\circ}$ should be shifted to a peak position approximately the $\theta$-degree frequency times $(\cos \theta)^{-1}$. The actual shift of the peak positions was in good agreement with the expected shift. The magnitude of the carrier density of $2 \mathrm{DEG}$ in the $\mathrm{Al}_{0.3} \mathrm{Ga}_{0.7} \mathrm{~N} / \mathrm{AlN} / \mathrm{GaN}$ heterostructure was larger than that in the $\mathrm{Al}_{0.3} \mathrm{Ga}_{0.7} \mathrm{~N} / \mathrm{GaN}$ heterostructure, which was in reasonable agreement with the results of the $\mathrm{Al}_{0.4} \mathrm{Ga}_{0.6} \mathrm{~N} / \mathrm{GaN}$ heterostructures with and without an AlN embedded potential barrier layer. ${ }^{12}$ The mobility of $2 \mathrm{DEG}$ in the $\mathrm{Al}_{0.3} \mathrm{Ga}_{0.7} \mathrm{~N} / \mathrm{AlN} / \mathrm{GaN}$ heterostructure with an AlN spacer layer is larger than that in the $\mathrm{Al}_{0.3} \mathrm{Ga}_{0.7} \mathrm{~N} / \mathrm{GaN}$ heterostructure.

The potential and the wavefunction of the $\mathrm{Al}_{0.3} \mathrm{Ga}_{0.7} \mathrm{~N} / \mathrm{GaN}$ and $\mathrm{Al}_{0.3} \mathrm{Ga}_{0.7} \mathrm{~N} / \mathrm{AlN} / \mathrm{GaN}$ heterostructures were calculated by solving the

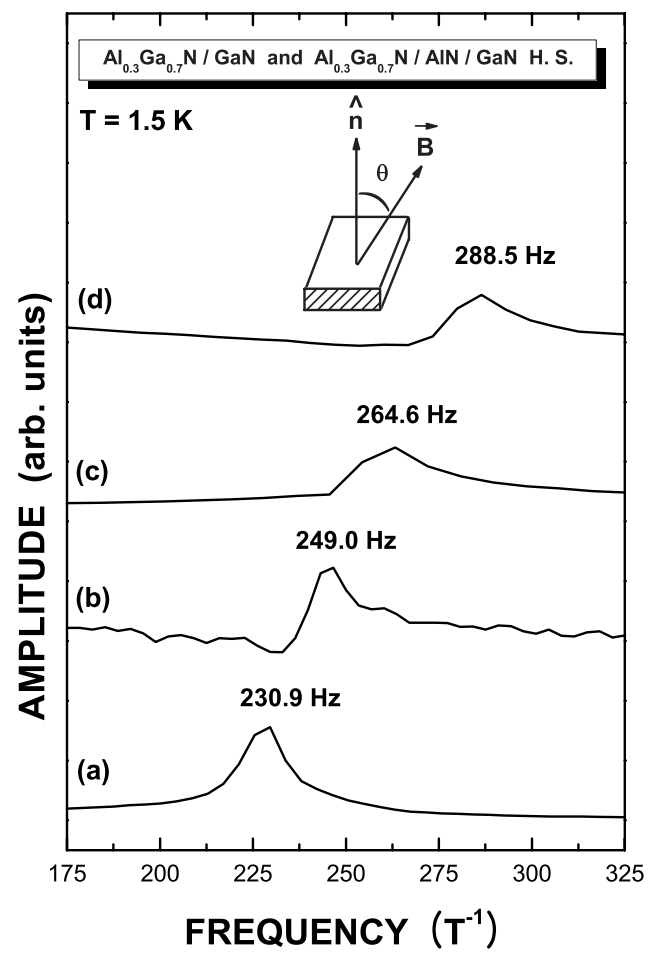

Fig. 2. Fast Fourier analyses of the $\mathrm{SdH}$ data for an $\mathrm{Al}_{0.3} \mathrm{Ga}_{0.7} \mathrm{~N} / \mathrm{GaN}$ heterostructure with (a) $\theta=0^{\circ}$ and (b) $\theta=22^{\circ}$ and for an $\mathrm{Al}_{0.3} \mathrm{Ga}_{0.7} \mathrm{~N} / \mathrm{AlN} / \mathrm{GaN}$ heterostructure with (c) $\theta=0^{\circ}$ and (d) $\theta=23.5^{\circ}$.

Schrdinger equation and Poisson equation selfconsistently, taking into account the spontaneous and piezoelectric polarization effects. The input physical parameters used in this calculation were taken from Ref. 15, except that the effective masses which were referred from Ref. 16, and are summarized in Table 1. The Fermi levels were chosen to give the electron densities determined from the $\mathrm{SdH}$ data.

When only the polarization charges are considered, there is no potential well to attract electrons even though there is a net positive polarization charge at the $\mathrm{Al}_{0.3} \mathrm{Ga}_{0.7} \mathrm{~N} / \mathrm{GaN}$ and the $\mathrm{AlN} / \mathrm{GaN}$ hetero-interfaces in the sample with an AlN barrier. Thus, we have to assume additional charges to form a potential well. There should be also additional charges to balance the experimentally observed 2DEG. There can be many possible boundary conditions and the corresponding self-consistent solutions depending on the distribution of these additional charges. We have tried two simple cases for the calculation of the electronic structures. In 
Table 1. Physical parameters of the $\mathrm{GaN}, \mathrm{AlN}$, and $\mathrm{Al}_{0.3} \mathrm{Ga}_{0.7} \mathrm{~N}$ layers used in the self-consistent calculation.

\begin{tabular}{lccc}
\hline Parameter & $\mathrm{GaN}$ & $\mathrm{AlN}$ & $\mathrm{Al}_{0.3} \mathrm{Ga}_{0.7} \mathrm{~N}$ \\
\hline Conduction band edge with respect to $\mathrm{GaN}(\mathrm{eV})$ & 0.0 & 1.897 & 0.4221 \\
Energy gap $(\mathrm{eV})$ & 3.42 & 6.13 & 4.023 \\
Electron effective mass & 0.2 & 0.48 & 0.242424 \\
Spontaneous polarization $\left(\mathrm{C} / \mathrm{m}^{2}\right)$ & -0.029 & -0.081 & -0.0446 \\
Piezoelectric polarization $\left(\mathrm{C} / \mathrm{m}^{2}\right)$ & 0.0 & -0.0506109 & -0.0112922 \\
Lattice constant $a(\AA)$ & 3.189 & 3.112 & 3.1659 \\
Elastic stiffness constant $C_{13}(\mathrm{GPa})$ & 103 & 108 & 104.5 \\
Elastic stiffness constant $C_{33}(\mathrm{GPa})$ & 405 & 373 & 395.4 \\
Piezoelectric modulus $e_{31}\left(\mathrm{C} / \mathrm{m}^{2}\right)$ & -0.49 & -0.6 & -0.523 \\
Piezoelectric modulus $e_{33}\left(\mathrm{C} / \mathrm{m}^{2}\right)$ & 0.73 & 1.46 & 0.949 \\
Dielectric constant & 9.5 & 9.0 & 9.35 \\
\hline
\end{tabular}

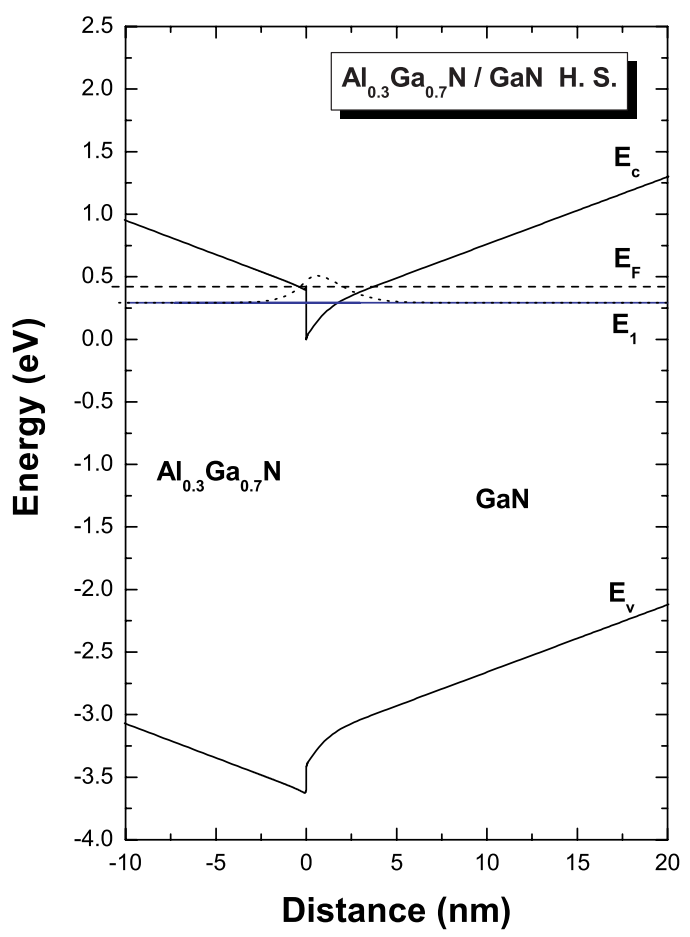

Fig. 3. Electronic subband structure of an $\mathrm{Al}_{0.3} \mathrm{Ga}_{0.7}$ $\mathrm{N} / \mathrm{GaN}$ heterostructure. $E_{1}, E_{\mathrm{F}}, E_{\mathrm{c}}$, and $E_{\mathrm{v}}$, represent the ground state energy, the Fermi energy, the conduction band edge, and the valence band edge, respectively.

one case, the charges to balance the interface polarization charges and the 2DEG are assumed to be equally divided at two end surfaces. In the other case, the charges existing at the two end surfaces are assumed to be distributed in such a way that the potentials of the two end surfaces are same. When

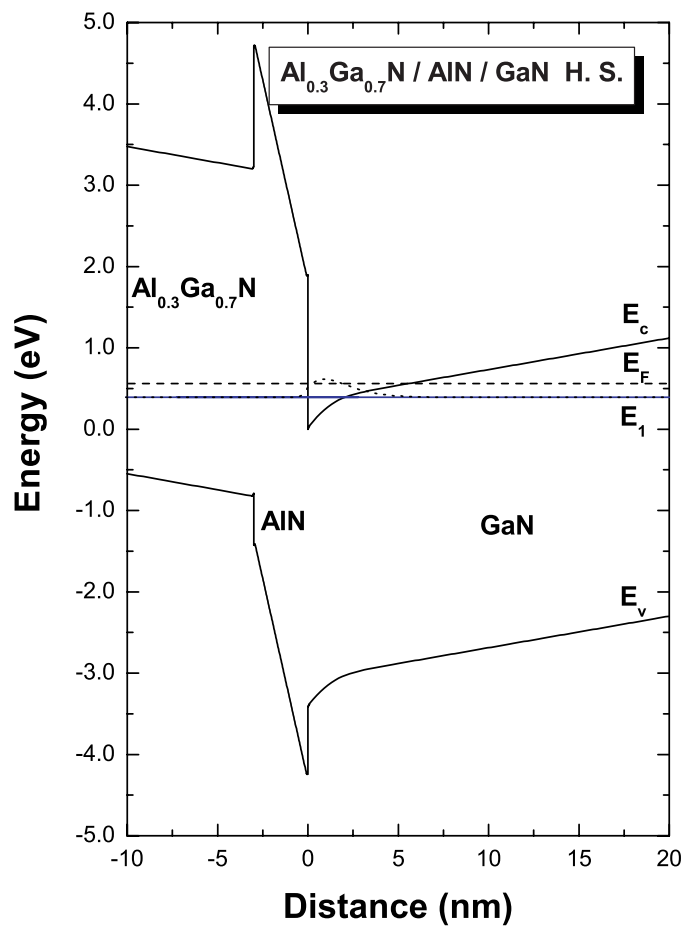

Fig. 4. Electronic subband structure of an $\mathrm{Al}_{0.3} \mathrm{Ga}_{0.7}$ $\mathrm{N} / \mathrm{AlN} / \mathrm{GaN}$ heterostructure. $E_{1}, E_{\mathrm{F}}, E_{\mathrm{c}}$, and $E_{\mathrm{v}}$, represent the ground state energy, the Fermi energy, the conduction band edge, and the valence band edge, respectively.

the electronic structures of the $\mathrm{Al}_{0.3} \mathrm{Ga}_{0.7} \mathrm{~N} / \mathrm{GaN}$ and the $\mathrm{Al}_{0.3} \mathrm{Ga}_{0.7} \mathrm{~N} / \mathrm{AlN} / \mathrm{GaN}$ heterostructures are calculated by using the second assumption, the two subbands occupying 2DEGs are located below the Fermi energy in the potential wells, which is inconsistent with the SdH data. Therefore, only the results 
of the electronic structures calculated by using the first assumption are shown in this paper.

Figures 3 and 4 show the self-consistent potentials and the wavefunctions together with the subband energies and the Fermi levels. The ground subband energy and the Fermi energy in the $\mathrm{Al}_{0.3} \mathrm{Ga}_{0.7} \mathrm{~N} / \mathrm{GaN}$ heterostructure determined from the bottom of the conduction band of the triangular potential well are 292 and $422 \mathrm{meV}$, respectively; the corresponding values in the $\mathrm{Al}_{0.3} \mathrm{Ga}_{0.7} \mathrm{~N} / \mathrm{AlN} / \mathrm{GaN}$ heterostructure are 391 and $542 \mathrm{meV}$, respectively. We note that the wavefunction of the 2DEG in the sample with AlN barrier is farther from the interface than that in the sample without AlN barrier, and this may be partly responsible for the higher mobility due to reduced interface scattering.

\section{Summary and Conclusions}

The carrier concentrations of 2DEG occupying the $\mathrm{Al}_{0.3} \mathrm{Ga}_{0.7} \mathrm{~N} / \mathrm{AlN} / \mathrm{GaN}$ and $\mathrm{Al}_{0.3} \mathrm{Ga}_{0.7} \mathrm{~N} / \mathrm{GaN}$ heterostructures at $1.5 \mathrm{~K}$, as determined from the $\mathrm{SdH}$ measurements, were $1.28 \times 10^{13}$ and $1.12 \times 10^{13} \mathrm{~cm}^{-2}$, respectively. The results of the angle-dependent $\mathrm{SdH}$ measurements at $1.5 \mathrm{~K}$ and FFT analyses clearly demonstrated that 2DEGs occupied one subband in triangular potential wells. The carrier density of the $2 \mathrm{DEG}$ in the $\mathrm{Al}_{0.3} \mathrm{Ga}_{0.7} \mathrm{~N} / \mathrm{AlN} / \mathrm{GaN}$ heterostructure was larger than that in the $\mathrm{Al}_{0.3} \mathrm{Ga}_{0.7} \mathrm{~N} / \mathrm{GaN}$ heterostructure. Possible subband structures for the $\mathrm{Al}_{0.3} \mathrm{Ga}_{0.7} \mathrm{~N} / \mathrm{AlN} / \mathrm{GaN}$ and the $\mathrm{Al}_{0.3} \mathrm{Ga}_{0.7} \mathrm{~N} / \mathrm{GaN}$ heterostructures were calculated by using a selfconsistent method and taking into account both the spontaneous and the piezoelectric polarizations. The present results show that an AlN embedded potential barrier layer can significantly alter the electronic parameters of the $\mathrm{Al}_{0.3} \mathrm{Ga}_{0.7} \mathrm{~N} / \mathrm{GaN}$ heterostructure.

\section{Acknowledgment}

This work was supported by the Korea Research Foundation Grant funded by the Korean Government (MOEHRD, Basic Research Promotion Fund) (KRF-2006-005-J04102).

\section{References}

1. S. Nakamura and G. Fasol, The Blue Laser Diode: GaN Based Light Emitters and Lasers (Springer, Berlin, 1997).

2. S. Nakamura, Science 281 (1998) 956.

3. S. Heikman, S. Keller, S. P. DenBaars and U. K. Mishra, Appl. Phys. Lett. 78 (2001) 2876.

4. Y. F. Wu, B. P. Keller, S. Keller, D. Kapolnek, P. Kozodoy, S. P. Denbaars and U. K. Mishra, Appl. Phys. Lett. 31 (1996) 1438.

5. O. Aktas, Z. F. Fan, S. N. Mohammad, A. Botchkarev and H. Morkoc, Appl. Phys. Lett. 69 (1996) 3872.

6. W. Lu, J. Yang, M. A. Khan and I. Adesida, IEEE Trans Electron. Dev. ED 48 (2001) 465.

7. L. K. Li, B. Turk, W. I. Wang, S. Syed, D. Simonian and H. L. Stomer, Appl. Phys. Lett. 76 (2000) 742.

8. T. W. Kim, D. C. Choo, Y. R. Jang, K. H. Yoo, M. H. Jung, Y. H. Cho, J.-H. Lee and J.-H. Lee, Solid State Commun. 132 (2004) 67.

9. Z. W. Zheng, B. Shen, Y. S. Gui, C. P. Jiang, N. Tang, R. Zhang, Y. Shi, Y. D. Zheng, S. L. Guo, G. Z. Zheng, J. H. Chu, T. Someya and Y. Arakawa, Appl. Phys. Lett. 82 (2003) 1872.

10. Z. W. Zheng, B. Shen, C. P. Jiang, Y. S. Gui, T. Someya, R. Zhang, Y. Shi, Y. D. Zheng, S. L. Guo, J. H. Chu and Y. Arakawa, J. Appl. Phys. 93 (2003) 1651.

11. N. Tang, B. Shen, Z. W. Zheng, J. Liu, D. J. Chen, J. Lu, R. Zhang, Y. Shi, Y. D. Zheng, Y. S. Gui, C. P. Jiang, Z. J. Qiu, S. L. Guo, J. H. Chu, K. Hoshino, T. Someya and Y. Arakawa, J. Appl. Phys. 94 (2003) 5420 .

12. T. W. Kim, D. C. Choo, K. H. Yoo, M. H. Jung, Y. H. Cho, J.-H. Lee and J.-H. Lee, J. Appl. Phys. 97 (2005) 103721.

13. U. K. Mishra, P. Parikh and Y. Wu, Proc. IEEE 90 (2002) 1022.

14. R. J. Justice, D. G. Seiler, W. Zawadzki, R. J. Koestner, M. Goodwin and M. A. Kinch, J. Vac. Sci. Technol. A 6 (1998) 2779.

15. O. Ambacher, J. Smart, J. R. Shealy, N. G. Weimann, K. Chu, M. Murphy, W. J. Schaff, L. F. Eastman, R. Dimitrov, L. Wittmer, M. Stutzmann, W. Rieger and J. Hilsenbeck, J. Appl. Phys. 85 (1999) 3222.

16. Y. Zhang and J. Singh, J. Appl. Phys. 85 (1999) 587. 